\title{
Ecosystem service trade-offs across global contexts and scales
}

\author{
$\underline{\text { Jeannine Cavender-Bares }}^{1}$, Patricia Balvanera $^{2},{\underline{\text { Elizabeth } \text { King }^{3}}}^{3}$ and $\underline{\text { Stephen Polasky }}^{4,5,6}$
}

\begin{abstract}
Meeting human needs while sustaining the planet's life support systems is the fundamental challenge of our time. What role sustenance of biodiversity and contrasting ecosystem services should play in achieving a sustainable future varies along philosophical, cultural, institutional, societal, and governmental divisions. Contrasting biophysical constraints and perspectives on human well-being arise both within and across countries that span the tropics and temperate zone. Direct sustenance of livelihoods from ecosystem services in East Africa contrasts with the complex and diverse relationships with the land in Mexico and the highly monetary-based economy of the United States. Lack of understanding of the contrasting contexts in which decision-making about trade-offs occurs creates impediments to collective global efforts to sustain the Earth's life support systems. While theoretical notions of the goals of sustainability science seek a unified path forward, realities on the ground present challenges. This Special Feature seeks to provide both an analytical framework and a series of case studies to illuminate impediments posed to sustainability by contrasting biophysical constraints and human perspectives on what should be sustained. The contributors aim to clarify the trade-offs posed to human welfare in sustaining biodiversity and ecosystem services and the challenges in managing for a sustainable future in which human well-being is not compromised as compared to today. Our goal is to provide novel insights on how sustainability can be achieved internationally through exploration of constraints, trade-offs, and human values examined at multiple scales, and across geographic regions from a range of cultural perspectives.
\end{abstract}

Key Words: biophysical constraints; cultural contexts; ecosystem services; empirical case studies; human preferences; sustainability framework; trade-offs

\section{INTRODUCTION}

Our aim in this Special Feature is to synthesize the relevant ecological and welfare economics literature to present a simple analytical framework for understanding the constraints and challenges of a sustainability transition across spatial scales and biophysical, cultural, and institutional contexts, and to apply the framework to a series of empirical case studies that traverse this range of contexts. We define sustainability as meeting the needs of current populations without compromising those of future generations, following the 1987 World Commission on Environment and Development chaired by Gro Harlem Brundtland. Inherent to this definition is the imperative to maintain the Earth's life support systems. The framework, which focuses on trade-offs between provisioning ecosystem services, on the one hand, and regulating services or biodiversity, on the other, helps reveal how the contrasting perspectives and needs of different stakeholders drive very different preferred and realized outcomes. Empirical analysis using this framework allows stakeholders to identify the biophysical constraints of natural systems in generating ecosystem services and to decipher the factors that underlie the discrepancies in management objectives among groups and governance regimes that impede sustainable outcomes. By modeling biophysical constraints, analyzing where a social-ecological system sits in relation to those constraints, and clarifying the values and preferences of a range of actors, the framework serves as a tool for a diversity of users that can help identify obstacles and enabling factors in advancing progress towards sustainability. Identification of the obstacles as well as enabling factors towards outcomes that enhance well-being for multiple actors should aid communication across groups and decision-makers in developing policies for sustainability.

The critical need to advance tools for communicating across contexts and scales is highlighted by readily apparent contrasts in biophysical regimes and economic wealth in nation states across the globe. These contrasts are exemplified by global patterns, which reveal that highest biodiversity is found where per capita wealth and measures of human well-being are lowest (Fig. 1). Thus, precisely where biodiversity is at its peak is where basic human needs are not met, which creates inevitable tensions between conservationist values at the global scale and preferences for provisioning services to meet basic needs at local scales. Separating the range of human values and preferences for ecosystem services from the biophysical reality of what services and components of natural capital can be supported in different regions enables discourse and helps illuminate the levers that can function to advance sustainability. Clarifying the difference between contrasting biophysical constraints and contrasting human needs and values across contexts is the core goal of this series of papers. In this editorial, we provide an overview of the conceptual framework and the empirical examples that make use of the framework in specific case studies. We then lay out the challenges ahead to operationalize the framework for meaningful advancement towards sustainability.

This Special Feature has its origins in a distributed graduate seminar on sustainability science, funded initially by the U.S. National Center for Ecological Analysis and Synthesis. The effort was catalyzed by the launching of the Institute on Environment at the University of Minnesota and by the 2009 All Scientists Meeting of the Long-Term Ecological Research Network. During that 3-year period, the sustainability science course involved more than 150 student, post doctoral, and faculty scholars from the Institute on Environment at the University of Minnesota, Harvard University's Kennedy School of Government, the Centro de Investigaciones en Ecosistemas at the Universidad Nacional Autónoma de Mexico in Morelia, Mexico, Princeton University, Arizona State's School of Sustainability, Columbia

\footnotetext{
${ }^{1}$ University of Minnesota, ${ }^{2}$ Centro de Investigaciones en Ecosistemas, Universidad Nacional Autónoma de México, ${ }^{3}$ University of Georgia, ${ }^{4}$ Department of Applied Economics, University of Minnesota, ${ }^{5}$ Department of Ecology, Evolution and Behavior, University of Minnesota,

${ }^{6}$ Institute on Environment, University of Minnesota
} 
Fig. 1. Across nation states around the globe, metrics of human well-being, wealth, and biodiversity reveal that the poorest countries have the lowest well-being but harbor the highest biodiversity. Health risks, as indicated by undernourishment (A), high child mortality rates (B), and shortened life spans (C) are associated with low per capita income, shown here as per capita gross national income (GNI) in US\$. Poverty is also associated with limited access to safe drinking water (D), high fertility rates (E), and low resource consumption, indicated here by energy use per capital in oil equivalents $(\mathrm{F})$. At the same time, low income countries harbor the highest biodiversity, shown here for bird diversity $(\mathrm{G})$, vascular plant diversity $(\mathrm{H})$, and mammal diversity (I). As a consequence, provisioning resources at the local scale are likely to be valued highly, while conservation of biodiversity, which represents a global service, is likely to be less valued. This presents an inherent challenge to managing for multiple ecosystem services that have benefits for many stakeholders locally and globally. Data are from the World Bank's health, nutrition, and population data and statistics (World Bank 2011a) and World Development Report (World Bank 2011b), and the World Resources Institute (2005) sourced from the United Nations Environment Programme-World Conservation Monitoring Centre; they are adapted and replotted from Cavender-Bares et al. (2013).
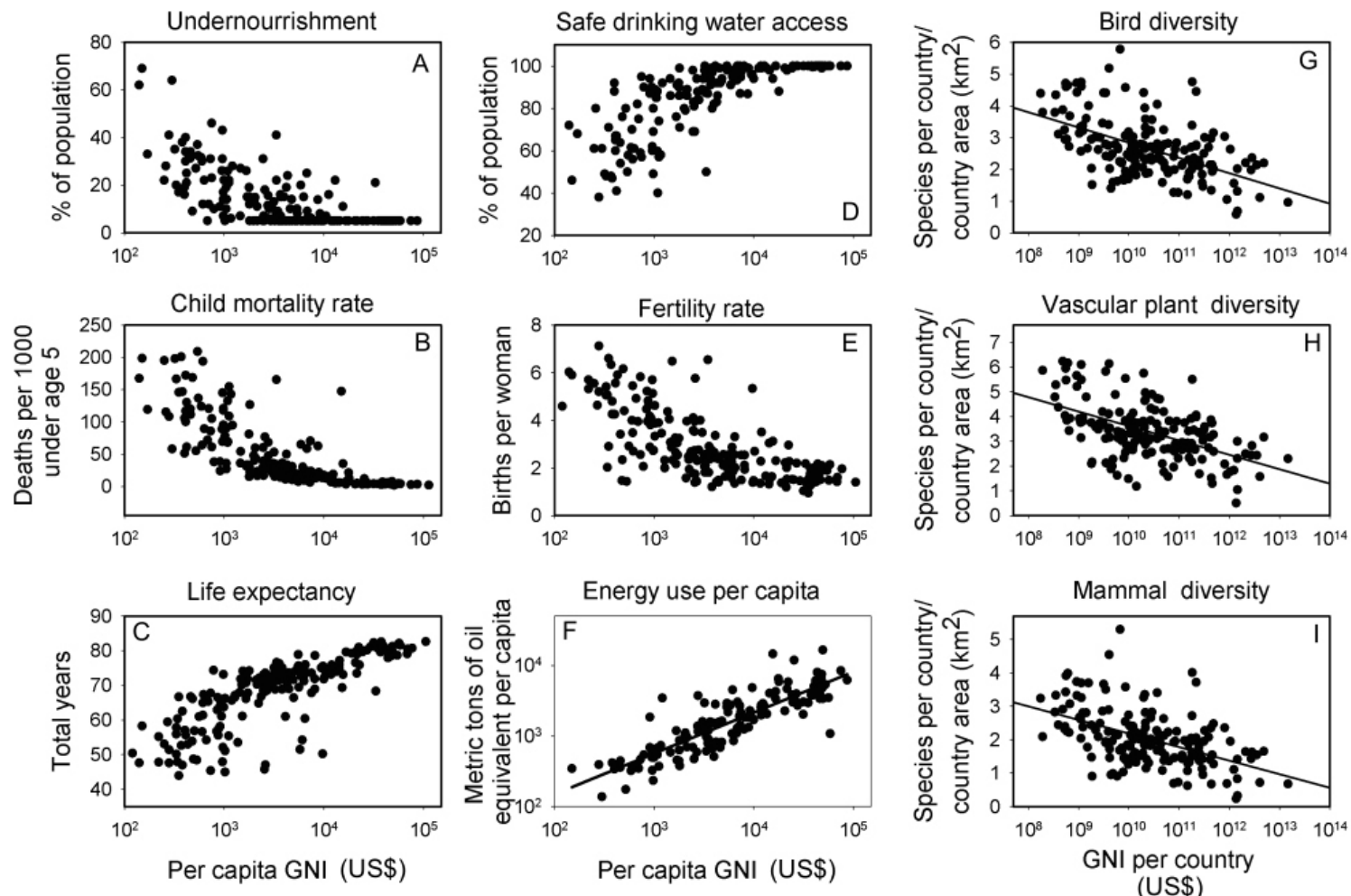

University's Earth Institute, and Florida International University. The cross-fertilization of ideas, particularly through sometimes heated exchanges between U.S. and Mexican students, sparked the idea for a special issue that examines trade-offs in ecosystem services across contexts and scales. Two conceptual papers that provide a foundation for empirical studies emerged from this effort (Cavender-Bares et al. 2015, E. King, J. Cavender-Bares, P. Balvanera, and S. Polasky, unpublished manuscript). Course participants and interested researchers developed a series of case studies from this conceptual framework.

\section{OVERVIEW OF THE FRAMEWORK}

Cavender-Bares et al. (2015) present a sustainability framework derived from a synthesis of economic and ecological literature, which integrates the ecological mechanisms that underpin ecosystem services, the biophysical trade-offs that constrain management options, the preferences and values of stakeholders, and the dynamic nature of these components. Trade-offs between and among biodiversity and provisioning, cultural, regulating, and supporting services are considered, and theoretical models are used to demonstrate the dynamic nature and consequences of such trade-offs by focusing on biodiversity and agricultural provisioning services. E. King, J. Cavender-Bares, P. Balvanera, and S. Polasky, unpublished manuscript evaluate the framework's potential utility in resource management and conflict resolution, and identify insights the framework can provide under different scenarios of trade-offs among stakeholders across cultures, contexts, and scales. Combined, these conceptual papers lay out a series of building blocks of the sustainability framework:

1. Trade-offs among ecosystem services emerge from the biophysical properties of ecosystems. These constraints, represented here in the form of trade-off curves or 
"efficiency frontiers" sensu Polasky et al. (2008), change across biophysical contexts and across spatial and temporal scales.

2. Thresholds and nonlinear dynamics in biophysical constraints make trade-offs among ecosystem services inherently difficult to navigate and manage.

3. Preferences for ecosystem services differ among stakeholders, given the relationships of those services to their well-being. These can be visualized as indifference curves, which when superimposed on the efficiency frontier can be used to identify more efficient and sustainable outcomes. Human preferences represented by these indifference curves vary across contexts, cultures, and scales.

4. Impediments and enabling factors to achieving efficient and sustainable ecosystem service outcomes emerge from a range of institutional and cultural factors that shift across scales within and across political borders. Assessing how current conditions relate to the efficiency frontier and to areas with highest sustainable outcomes can foster the assessment of such impediments and enabling factors.

5. Sustainable outcomes must be considered in the context of their temporal dynamics, given the dynamic nature of biophysical constraints and ecosystem service benefits that can result in (for example) temporal lags and intergenerational inequities.

\section{EMPIRICAL CASE STUDIES}

These two conceptual papers set the stage for a series of case studies that confront these issues with empirical data in the context of the ag-industrial corn belt of the upper Midwestern United States, agroecosystems in Mexico, ecotourism in Costa Rica, land use scenarios in the Dry Chaco region of Argentina and rural Paraguay, and pastoralist societies in central Kenya. The case studies cover a wide range of biophysical and societal conditions, with a core focus on the assessment of trade-offs between provisioning ecosystem services and regulating services or other components of natural capital, including biodiversity.

A common theme revealed by these studies is that management practices could be improved to enhance both provisioning and regulating services to the benefit of all stakeholders. The muchdebated trade-off between water quality and corn production, the largest agricultural crop in the United States in terms of land area and revenue, is tackled by Ewing and Runck (2015). Their analysis reveals that currently feasible management and technological shifts would both increase the production of corn and enhance water quality. In Mexican agroecological systems studied by González-Esquivel et al. (2015), provisioning services in terms of staple crop production for self-subsistence and local markets, on the one hand, and avocado cash crops for the export market, on the other hand, trade off with soil quality, pest and pollinator regulation, water quality, and biodiversity. The study reveals that management decisions of farmers are driven largely by export markets, costs of agricultural inputs, and climatic factors but not by negative consequences of management practices for regulating services or biodiversity. Like Ewing and Runck (2015), they too demonstrate that alternative management practices could increase both the provisioning services that sustain livelihoods and the regulating services that allow long-term sustainability. In step with these studies, Grossman (2015) shows that in smallholder farms in eastern Paraguay, where subsistence provisioning of agricultural and forestry products trade off with regulating services and biodiversity, most landholders are inefficient in their land management. Empirically based models of the efficiency frontier reveal that both greater yields and greater regulating services should be possible.

Several studies were able to apply to framework to examine both the biophysical constraints of ecosystem service trade-offs and the contrasting values of competing stakeholders using empirical approaches. Mastrangelo and Laterra (2015) examine ecosystem services and land use practices in agricultural frontiers of the Argentine Dry Chaco region, and focus on observed trade-offs between avian habitat and agricultural productivity. Under five contrasting policy scenarios, they simulate biophysical outcomes that would enhance both regulating and provisioning services. At the same time, they examine contrasting stakeholder preferences in relation to the observed and simulated biophysical outcomes, and reveal stark differences in the benefits achieved for different stakeholders under different policy scenarios. They conclude that exogenous incentives and regulations would be necessary to achieve outcomes that advance sustainability and optimize benefits to multiple stakeholders. Regarding Mexican tropical dry forest agroecological systems, F. Mora, P. Balvanera, E. GarcíaFrapolli, A. Castillo, J. Trilleras, and D. Cohen, unpublished manuscript examine the nature of the trade-offs between fodder for cattle ranching and carbon stocks or biodiversity conservation alongside the contrasting preferences of key stakeholders for these services. They demonstrate that management is now either aimed at maximizing biodiversity and carbon stocks, or maximizing fodder, but other management decisions lead to intermediate levels of carbon and fodder. They show that more sustainable outcomes that allow both greater fodder provisioning and higher biodiversity are possible with altered management practices. They identify obstacles that prevent such practices, as well as opportunities for shifting practices that would enhance benefits for multiple stakeholders who live and work in this system. Allen (2015) models regional changes in forest cover in Monetverde Costa Rica over a 25-year period during the rise of the nature tourism industry, and uses interview data with landholders to understand their ecosystem service preferences and the drivers of land use change. She shows that nature tourism can render provisioning services to landowners while maintaining or enhancing regulating services from forests under some conditions, but cautions that it also has the potential to complicate livelihood sustainability and compromise regulating services of tropical forests.

Finally, regarding pastoralist systems in Kenya, Kaye-Zwiebel and King (2014) emphasize the importance of careful examination of perceptions and values that communities place on ecosystem services when developing policies and planning for sustainable management. Their analyses of five culturally similar pastoral communities reveal substantial variability in perceptions of forage and livestock scarcity, differences in the nature and degree of traditional forms of social capital exhibited in each community, and important differences in how communities value economic versus ecological benefits from conservation areas. Reminiscent of Ostrom et al.'s (2007) call to go "beyond panaceas," they caution that no single strategy for sustainable resource use in these pastoralist systems may work for all communities. 
The case studies in this Special Feature traverse a range of biophysical conditions from the cold temperate Midwestern United States to the high-elevation temperate regions of central Mexico and eastern Paraguay, the dry tropical regions of western Mexico, northern Argentina, and central Kenya, and the montane humid tropics of Costa Rica. All of the studies encompass rural areas, and many of these have largely agrarian economies. The highest population densities are found in the Midwestern United States, followed by intermediate densities in central and western Mexico, and lowest densities in northwestern Costa Rica, eastern Paraguay, northern Argentina, and central Kenya. The case studies likewise traverse a range of economic conditions and per capita wealth. The U.S. study by Ewing and Runck (2015) is nested within an area of the world where per capita gross domestic product (GDP) is very high. The studies in western Mexico (F. Mora, P. Balvanera, E. García-Frapolli, A. Castillo, J. Trilleras, and D. Cohen, unpublished manuscript), Paraguay (Grossman 2015), Argentina (Mastrangelo and Laterra 2015), central Mexico (González-Esquivel et al. 2015), and Costa Rica (Allen 2015) are all areas with intermediate GDP, while the central Kenyan study (Kaye-Zwiebel and King 2014) is in an area with low per capita GDP.

The focal provisioning services, the ways in which ecosystems are managed, the intensity of management, and the management outcomes are also wide ranging. Management regimes range from intensive corn production in the Midwestern United States to the semi-intensive cattle ranching in northern Argentina, one of the key areas for high cattle meat production in the world. The very lucrative avocado cash crop in central Mexico contrasts sharply with the subsistence maize production there, and the case study in western Mexico addresses low intensity and low productivity cattle ranching. Low intensity agriculture and cattle ranching for subsistence as well as for markets, interspersed with eucalyptus plantations and forest conservation, is analyzed in eastern Paraguay. Extensive ranching in native grasslands is a central feature of the livelihoods of the inhabitants of central Kenya. In Costa Rica, ecotourism has been growing and intensifying, often taxing the local resource base, alongside efforts to conserve forested lands and biodiversity.

The case studies focus on different sections of the analytical framework presented in the first two conceptual papers, and harness a wide variety of data sources and approaches. Using remote sensed data and models of forest recovery, Allen (2015) documents the impacts of nature tourism on forest cover; she describes the shapes of different efficiency frontiers from interview data and discusses their associated economic and community impacts. Grossman (2015) calculates ecosystem services from interview data, models the efficiency frontiers in which maximum potential service could be obtained, and compares these with realized conditions; he discusses the socioeconomic, historical, and cultural conditions that have enabled or hindered the attainment of potential conditions. Ewing and Runck (2015) model the services within grid cells and contrast the observed efficiency frontier with those in which nitrogen use is optimized. They then assess the range of resulting services in different municipalities and examine the biophysical and socioeconomic drivers that underlie contrasting outcomes, highlighting the importance of spatial scale. Using field farm data, González-Esquivel et al. (2015) describe bivariate and multivariate trade-offs among ecosystem services; from interviews, they assess what biophysical, economic, and policy drivers drive management and these trade-offs. Mastrangelo and Laterra (2015) describe the shape of the observed efficiency frontier from field data and model changes in it under alternative future scenarios of land use change; they superimpose the utility curves for different stakeholders with the efficiency frontier and identify opportunities for desirable outcomes under future scenarios that fit the needs of different stakeholders. F. Mora, P. Balvanera, E. García-Frapolli, A. Castillo, J. Trilleras, and D. Cohen, unpublished manuscript proceed in similar ways, though rather than contrasting alternative future scenarios, they assess how changes in the shape of the efficiency frontier and those in the preferences of stakeholders are feasible as a result of technological and educational interventions. Kaye-Zwiebel and King (2014) focus on how the services and the trade-offs among them are perceived by the local stakeholders, and assess how ecosystem services are perceived to contribute to different components of well-being.

All of the study cases explore how a sustainability transition could occur. Allen (2015) identifies win-win opportunities for nature tourism and conservation when livelihood opportunities are compatible with forest regrowth. Ewing and Runck (2015) identify specific municipalities where nitrogen application is optimized, leading to higher corn yields and cleaner water, thereby demonstrating potential feasibility of more sustainable outcomes for other municipalities. F. Mora, P. Balvanera, E. GarcíaFrapolli, A. Castillo, J. Trilleras, and D. Cohen, unpublished manuscript show how changes in cattle ranching management practices and stakeholders' preferences are feasible and can provide alternatives to sustain biodiversity, carbon stocks, and fodder production. Grossman (2015) examines the conditions under which land use is optimized, allowing increased agricultural productivity and biodiversity conservation. Mastrangelo and Laterra (2015) provide examples of how different stakeholders are able to increase agricultural productivity or biodiversity conservation without compromising the other. GonzalezEsquivel et al. (2015) show how sustainable agriculture production could be fostered through technical and educational interventions to foster biodiversity conservation, reduce soil erosion, and increase soil quality. Finally, Kaye-Zwiebel and King (2014) emphasize the importance of social capital in governing for sustainability, and argue that local stakeholders' perceptions of, and values for, different ecosystem services can inform the management options most likely to succeed for each community.

\section{LOOKING FORWARD}

Taken together, these case studies illustrate how the simple analytical framework can be operationalized to assess the sustainability of current management practices and to gain insights into the obstacles and enabling factors that can facilitate transitions to outcomes that maximize the sustenance of ecosystem functions and human well-being over the long term.

We note, however, some limitations in the current presentations, and hope these can be overcome in the near future. All of these case studies focus on a very limited set of ecosystem services at regional spatial scales. These are generally presented in two dimensions for ease of analysis and comprehension. Actual management challenges deal with whole portfolios of ecosystem services that may be positively or negatively associated with each other and which contribute to human well-being in contrasting 
and complex ways. Also, all the case studies focus on local to landscape scales. Analyzing regional and global trade-offs between ecosystem services and human preferences remains a daunting task. The different scales at which various services are rendered and at which they contribute to human-well being need to be addressed. While the framework explicitly attempts to incorporate the dynamic nature of ecosystem service trade-offs and human preferences for them, modeling the dynamics of social-ecological systems in a realistic and predictive manner remains an enormous challenge. The complex cross-scale interactions among enabling factors and obstacles towards sustainability, such as local technological scale and tenure rights or global market prices and global tourism, within each particular context, still need to be more clearly understood. Finally, human well-being depends on other forms of capital beyond ecosystems and natural capital. Assessing the relative contributions of social capital, manufactured capital, institutions, and other forms of capital that contribute to human well-being along with natural capital will certainly provide insights towards sustainability.

In closing, the analytical framework and the case studies presented here simultaneously address the contributions of biophysical conditions and stakeholders' preferences and needs, as well as the social, economic, and political enabling factors towards sustainability. We hope our initial efforts down this path will spark further investigation and interdisciplinary thinking, and provide a tool to bring diverse actors together with a common language and approach. However, we are fully aware of the long road ahead in applying these advances towards a sustainability transition. Importantly, the local to global assessment of sustainability that encompass all forms of capital, as envisioned by Arrow et al. $(2004,2012)$, remain to be developed. The identification and implementation of social, economic, cultural, and policy changes are needed to better navigate conflicting needs among stakeholders at local to global scales in close collaboration with the full range of stakeholders. This is the challenge of sustainability science in the coming decades.

Responses to this article can be read online at: http://www.ecologyandsociety.org/issues/responses. $\mathrm{php} / 7137$

\section{Acknowledgments:}

We thank the National Center for Ecological Analysis and Synthesis and the University of Minnesota Institute on Environment for support. We also thank the Long-Term Ecological Research Network funded by the U.S. National Science Foundation for supporting a catalysis meeting that initiated this effort. Students, post docs, and faculty participants of the Sustainability Science Distributed Graduate Seminar across multiple institutions contributed to the goals and ideas presented in this Special Feature.

\section{LITERATURE CITED}

Allen, K. E. 2015. Trade-offs in nature tourism: contrasting parcel-level decisions with landscape conservation planning. Ecology and Society 20(1): 21. http://dx.doi.org/10.5751/ ES-07058-200121
Arrow, K., P. Dasgupta, L. Goulder, G. Daily, P. Ehrlich, G. Heal, S. Levin, K.-G. Mäler, S. Schneider, D. Starrett, and B. Walker. 2004. Are we consuming too much? Journal of Economic Perspectives 18:147-172. http://dx.doi.org/10.1257/0895330042162377

Arrow, K., P. Dasgupta, L. H. Goulder, K. J. Mumford, and K. Oleson. 2012. Sustainability and the measurement of wealth. Environment and Development Economics 17:317-353. http://dx. doi.org/10.1017/S1355770X12000137

Cavender-Bares, J., J. Heffernan, E. King, S. Polasky, P. Balvanera, and W. C. Clark. 2013. Sustainability and biodiversity. Pages 7184 in S. Levin, editor. Encyclopedia of biodiversity. Elsevier, Oxford, UK. http://dx.doi.org/10.1016/B978-0-12-384719-5.00390-7.

Cavender-Bares, J., S. Polasky, E. King, and P. Balvanera. 2015. A sustainability framework for assessing trade-offs in ecosystem services. Ecology and Society 20(1): 17. http://dx.doi.org/10.5751/ ES-06917-200117

Ewing, P. M., and B. C. Runck. 2015. Optimizing nitrogen rates in the midwestern United States for maximum ecosystem value. Ecology and Society 20(1): 18. http://dx.doi.org/10.5751/ ES-06767-200118

González-Esquivel, C., M. Gavito, M. Astier, M. CadenaSalgado, E. del Val, L. Villamil-Echeverri, Y. Merlín-Uribe, and P. Balvanera. 2015. Ecosystem service trade-offs, perceived drivers and sustainability in contrasting agroecosystems in central Mexico. Ecology and Society, in press.

Grossman, J. J. 2015. Ecosystem Service Trade-offs and Land Use among Smallholder Farmers in Eastern Paraguay. Ecology and Society 20(1):19. http://dx.doi.org/10.5751/ES-06953-200119

Kaye-Zwiebel, E., and E. King. 2014. Kenyan pastoralist societies in transition: varying perceptions of the value of ecosystem services. Ecology and Society 19(3):17. http://dx.doi.org/10.5751/ ES-06753-190317

Mastrangelo, M. E., and P. Laterra. 2015. From biophysical to social-ecological trade-offs: integrating biodiversity conservation and agricultural production in the Argentine Dry Chaco. Ecology and Society 20(1):20. http://dx.doi.org/10.5751/ES-0718-200120

Ostrom, E., M. A. Janssen, and J. M. Anderies. 2007. Going beyond panaceas. Proceedings of the American Academy of Sciences of the United States of America 104(39):15176-15178. http://dx.doi.org/10.1073/pnas.0701886104

Polasky, S., E. Nelson, J. Camm, B. Csuti, P. Fackler, E. Lonsdorf, C. Montgomery, D. White, J. Arthuri, B. Garber-Yonts, R. Haight, J. Kagan, A. Starfield, and C. Tobalske. 2008. Where to put things? Spatial land management to sustain biodiversity and economic returns. Biological Conservation 141:1505-1524. http:// dx.doi.org/10.1016/j.biocon.2008.03.022

World Bank. 2011a. Health, nutrition and population data and statistics. [online] URL: http://datatopics.worldbank.org/hnp/

World Bank. 2011b. World development report. [online] URL: _ https://openknowledge.worldbank.org/handle/10986/2124

World Resources Institute. 2005. Data tables 10: biodiversity. United Nations Environment Programme-World Conservation Monitoring Centre. [online] URL: http://pdf.wri.org/ $\underline{\text { wrr05 dt all.pdf }}$ 